\title{
UNA DOLOROSA CASTELLANA, OBRA DEL ESCULTOR VALLISOLETANO PEDRO DE ÁVILA, EN LA IGLESIA DE SAN MARCOS DE SEVILLA
}

\author{
A CASTILIAN VIRGIN OF SORROWS, A MASTERPIECE \\ OF THE VALLISOLETANO SCULPTOR PEDRO DE ÁVILA, \\ AT THE CHURCH OF SAN MARCOS IN SEVILLE
}

\author{
JAVIER BALADRÓN \\ balilla19@hotmail.com \\ José CARLOS BRASAS \\ Universidad de Salamanca. España \\ caegido@ono.com
}

\begin{abstract}
El presente artículo pretende dar a conocer un busto de Dolorosa conservado en la sevillana iglesia de San Marcos que, procedente de tierras castellanas, se puede atribuir con bastante certeza a la familia de escultores barrocos vallisoletanos Ávila, y más concretamente a Pedro de Ávila, el mejor artífice de la escuela vallisoletana del primer tercio del siglo XVII.

Palabras clave: Barroco; escultura; Pedro de Ávila; Sevilla; Valladolid.
\end{abstract}

The current paper aims to publish a bust of Virgin of Sorrows preserved at the Sevillian Church of San Marcos. This work of art, which comes from Castile, can be widely attributed to the Ávila, a family of Vallisoletanos baroque sculptors. Most specifically to Pedro de Ávila, the best author of the Vallisoletana School during the first third of the $17^{\text {th }}$ century.

Keywords: Baroque; sculpture; Pedro de Ávila; Seville; Valladolid.

En la iglesia de San Marcos de Sevilla se conserva un busto de Dolorosa $(62 \mathrm{x}$ $45 \mathrm{~cm})^{1}$ (Figuras 1-2) de escuela vallisoletana que cabe atribuir a Pedro de Ávila, el

\footnotetext{
${ }^{1}$ Queremos agradecer la medición del busto a Jesús Romanov López-Alfonso.
} 
mejor artífice con el que contó la ciudad del Pisuerga durante el primer tercio del siglo XVIII. Tan solo sabemos de ella que fue donada a la iglesia sevillana hace $10 \mathrm{o}$ 12 años por un sacerdote vallisoletano que la tenía colocada en su oratorio privado. Actualmente se encuentra en el altar mayor a los pies de un Crucifijo.

Pero, ¿quién fue Pedro de Ávila? Los Ávila fueron una de las grandes familias de escultores barrocos vallisoletanos ${ }^{2}$. Formada por Juan (1652-1702) y sus hijos Pedro (1678- h. 1755) y Manuel (1690-1733), su producción se expandió por buena parte del noroeste español: desde Orense hasta Pamplona, pasando por Santillana del Mar, Oñate y la práctica totalidad de las provincias castellano y leonesas. Esta amplia propagación nos muestra bien a las claras la alta estima de la que gozaron estos escultores, a través de los cuales podemos observar la evolución experimentada por la escultura vallisoletana desde la plena influencia de Gregorio Fernández -aunque con la introducción de un movimiento ya plenamente barroco, así como otros estilemas propios- presente en Juan de Ávila, a la ruptura con esta tradición protagonizada por Pedro de Ávila, el cual adopta modos y maneras dieciochescas derivadas de las influencias cortesanas. Por su parte, Manuel de Ávila al formarse con su hermano Pedro toma los rasgos estilísticos de éste si bien se percibe en él cierta libertad y regusto pre-rococó.

Pedro de Ávila nació en Valladolid en 1678, siendo el cuarto de los hijos del matrimonio formado por el escultor Juan de Ávila y Francisca Ezquerra. Se formó con su padre, al cual ayudaría en alguna de sus grandes empresas, como el retablo mayor de la iglesia de Santiago de Valladolid (1698-1702), y posteriormente hacia 1700 con Juan Antonio de la Peña, otro de los grandes escultores vallisoletanos de la segunda mitad del siglo XVII y su futuro suegro ${ }^{3}$. Con estos dos maestros, herederos de la tradición de Gregorio Fernández, Pedro de Ávila estaba encaminado a ser un maestro de similares características; sin embargo, un supuesto viaje a Madrid (entre 1705-1707)4, solo cabe esa posibilidad, cambió su rumbo, ya que allí recibiría diversas influencias - madrileña, andaluza, italiana-, pues por entonces la capital de España era un crisol. El elemento más destacado que aprendió en Madrid fue el "pliegue a cuchillo" o "pliegue berninesco", del cual fue su introductor en la escuela castellana hacia 1714. Este paño de configuración tan aristada, que surgiría en Madrid por la influencia de las esculturas

2 MARTÍN GONZÁLEZ, Juan José: Escultura barroca castellana. Madrid, 1959, pp. 320-325; MARTÍN GONZÁLEZ, Juan José: Escultura barroca en España, 1600-1770. Madrid, 1991, pp. 79-81 y 447-449; BALADRÓN ALONSO, Javier: Los Ávila: una familia de escultores barrocos vallisoletanos [Tesis doctoral]. Universidad de Valladolid, 2016.

${ }^{3}$ Los tres grandes escultores del último cuarto del siglo XVII en la escuela vallisoletana son Juan de Ávila, Juan Antonio de la Peña y José de Rozas. Estos dos últimos aún trabajarían unos cuantos años del siglo XVIII si bien se verían superados enseguida por Pedro de Ávila.

${ }^{4}$ BALADRÓN ALONSO, J.: Los Ávila..., op. cit., p. 837. 
napolitanas, aportaba mayor dinamismo y vértigo a las composiciones. De ahí, y de las diversas esculturas de Pedro de Mena y José de Mora que se conservaban en la Villa y Corte, sería de dónde aprendería esta técnica el artífice vallisoletano.

Tras volver a la capital del Pisuerga se convertiría en poco tiempo en el escultor de mayor prestigio del foco vallisoletano, llegando a ocupar cargos como el de maestro mayor de escultura del obispado de Valladolid. Su supremacía abarcó todo el primer tercio del siglo XVIII. Ya en la década de 1730 el escultor riosecano Pedro Sierra tras su aprendizaje en los Reales Sitios y en Toledo iría ganándole poco a poco la partida, hasta que en 1739 el anciano escultor quedó ciego. Entre su numerosa obra, de la cual hay poca documentada -aunque su estilo es tan particular que apenas presenta problemas de identificación-, destacan el San José con el Niño (1714) de la catedral de Valladolid y las imágenes de San Pedro, San Pablo, la Magdalena, el Cristo del Olvido y la Inmaculada (1720) para el Oratorio de San Felipe Neri de la misma ciudad. Las dos últimas piezas están consideradas, con toda razón, como sus obras maestras.

Además del busto que presentaremos continuación, a Pedro de Ávila se le atribuyen con plena seguridad otros cuatros cuatro bustos de Dolorosa, además de la Virgen del Refugio conservada en la vallisoletana parroquia de El Salvador que puede ser considerada una derivación de esta tipología: se trata de los del Monasterio de San Quirce, Monasterio de Santa Brígida y Museo Nacional de Escultura (Figura 3), todos ellos en Valladolid, y el de la Fundación Caja Cantabria de Santillana del Mar (Cantabria) (Figura 4). Todos ellos son similares entre sí, aunque cada uno con ciertas peculiaridades; y, además, el busto sevillano posee similares características a los anteriormente referidos: con todas ellas coincide en la disposición de los brazos y en la mirada hacia el cielo.

En definitiva, se trata de un busto de tamaño cercano al natural realizado en madera policromada al pulimento. Está cortado horizontalmente un poco por debajo de la cintura, de tal manera que la aparición del manto en la parte baja proporciona una base y estabilidad a la pieza. La visión de la escultura es totalmente frontal, a pesar de lo cual se trata de una imagen que transmite cierto dinamismo.

Este busto de Dolorosa, al igual que el resto que se atribuyen a Pedro de Ávila, está directamente inspirado en la Dolorosa de la Vera Cruz que Gregorio Fernández realizó para el paso procesional del Descendimiento (1623) de la cofradía penitencial de la Santa Vera Cruz de Valladolid. De ella toma la composición general, la vestimenta y la manera de levantar la mirada hacia el cielo buscando la visión del Hijo muerto siendo descendiendo de la cruz. Hay que reseñar que Pedro de Ávila llegó a realizar alguna copia literal de Fernández, si bien en ocasiones como en ésta tan solo se inspiró en su obra para a partir de ahí realizar una escultura más personal.

La Virgen se lleva la mano derecha al pecho de una manera muy elegante y transmitiendo una profunda sensación de dolor contenido. No hemos de olvidar 
que se trata de una Dolorosa al pie de la cruz. Por su parte, la mano izquierda la levanta levemente realizando un típico gesto declamatorio. Se trata de unas manos muy delicadas y que forman una diagonal típicamente barroca, en la que sus dedos siguen un modelo estereotipado que es constante en la obra de Ávila: el pulgar y el meñique los mantiene casi inmóviles; en cambio, con el índice y el medio realiza una "V", teniendo el primero de ellos algo doblado y el segundo estirado; por su parte, el anular lo dobla hacia abajo. Desconocemos si las manos están talladas en el propio cuerpo o bien esculpidas aparte y unidas al conjunto mediante un vástago.

Viste túnica roja ceñida a la cintura por un cíngulo. Ávila simula a la perfección los numerosos pequeños pliegues formados por el ajustado entallado del cíngulo. Por encima tiene echado un manto azul que le cubre la cabeza, la espalda y parte del vientre. Por debajo del manto, tiene sobre la cabeza un pañuelo blanco que esconde por completo los cabellos. Este pañuelo se encuentra extendido de tal manera que cae en dos franjas a ambos lados del rostro hasta cruzarse a la altura del pecho; una de estas franjas se prolonga hasta el cíngulo, el cual sirve para recogerlo. La policromía de todas estas prendas está realizada con colores planos, si bien en los bordes de las mangas y del cuello se observa una pequeña cenefa dorada.

El rostro adquiere los estilemas propios del escultor durante su segunda etapa, en la cual ya ha pasado por Madrid y posee un estilo más personal y evolucionado, pero a la vez estereotipado, motivo por el cual es muy sencilla la identificación de nuevas obras del maestro vallisoletano. Esta estereotipación no será pura, puesto que en el rostro de cada escultura introduce ciertos matices para crear diversidad. Así, el rostro acusa un perfecto juego de calidades. La forma de la cabeza tiende al rectángulo, si bien en las figuras femeninas, como es el caso, abandona la rectitud de la parte inferior en pos de una curva pronunciada con algo de papada y un potente mentón. La frente es amplia y despejada. Los ojos, realizados en tapilla vítrea, son almendrados y con cierto rehundimiento. Cejas rectas con el ceño liso. Nariz recta, potente y geometrizada, con el tabique nasal ancho y aplastado; desde la parte superior de la nariz hasta la inferior va creciendo en anchura, formando algo parecido a un triángulo isósceles. Las aletas nasales están levemente pronunciadas mientras que las fosas nasales van perforadas, detalle que aporta un mayor grado de realismo. Esta forma tan característica de nariz es uno de los elementos que más ayudan a identificar las obras de este maestro. Boca pequeña y entreabierta en la cual podemos observar la fila de dientes superior. Los labios son muy finos y con las comisuras pronunciadas. Pómulos algo abultados y con entonaciones rosáceas.

Las prendas presentan el consabido pliegue a cuchillo. Es especialmente destacable la finura que logra en la parte superior del manto, la que le cubre la cabeza. Llega a adelgazar la madera de forma tan virtuosa que no puede por menos 
de recordarnos las creaciones de Pedro de Mena, especialmente los bustos de Dolorosa.

Dado el tamaño y su visión frontal es probable que este busto estuviera en origen dentro de un escaparate y que hiciera pareja con un Ecce Homo, algo muy usual en la escultura barroca castellana, y también en la andaluza. No es fácil determinar una cronología, puesto que solo contamos con el pliegue a cuchillo para poder delimitarla un poco: Ávila comienza a utilizarlo hacia 1714 y en 1739 ya no trabajaba, puesto que se había quedado ciego. Como con el paso de los años los pliegues a cuchillo los fue haciendo más profundos, y en esta pieza no son excesivamente cortantes, podríamos establecer una cronología hacia 1714-1725.

Aunque se trata de una escultura de bastante calidad, no llega al nivel excelso y de gran minuciosidad que Pedro de Ávila logra en la mayoría de sus creaciones personales, por lo que no podríamos perder de vista otras dos opciones: que se trate de una obra con amplia participación de taller en la que el maestro dio las pautas y la ejecución corrió a cargo en su práctica totalidad de los oficiales; o bien, que hubiera sido realizada por su hermano Manuel, el cual se formó a su lado. Su personalidad artística se nos muestra aún en la penumbra, dado que siempre permaneció a la sombra de su hermano. De él podemos decir que posee los estilemas del hermano aunque con unas formas menos aristadas. Además, el rostro, y especialmente la forma de la nariz y la boca de la Virgen, son similares a los de algunas de sus obras, como puede ser el San Isidro del retablo mayor de Fuentes de Valdepero (Palencia).

Fecha de recepción: 5 de enero de 2017

Fecha de aceptación: 20 de enero de 2017 


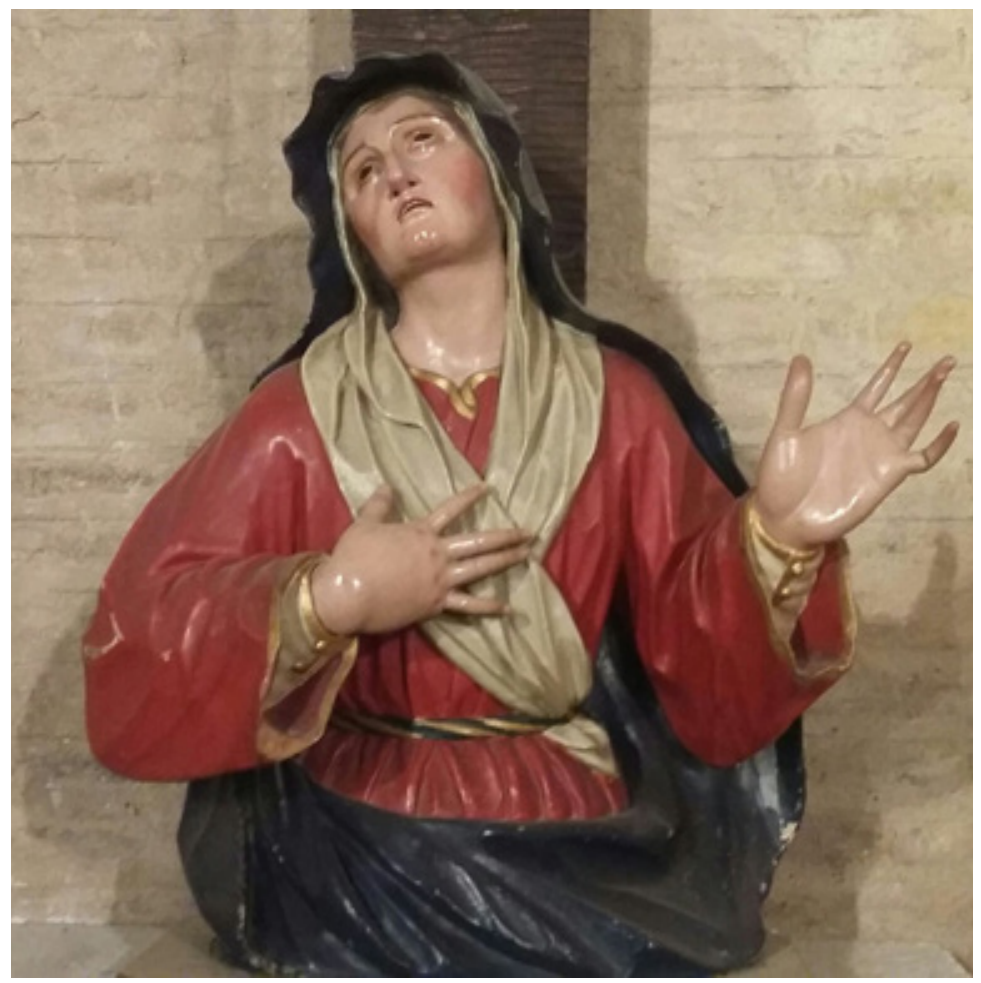

Figura 1. Atribuido a Pedro de Ávila, Busto de Dolorosa, hacia 1714-1725, parroquia de San Marcos, Sevilla. Foto: Jesús Romanov López-Alfonso.

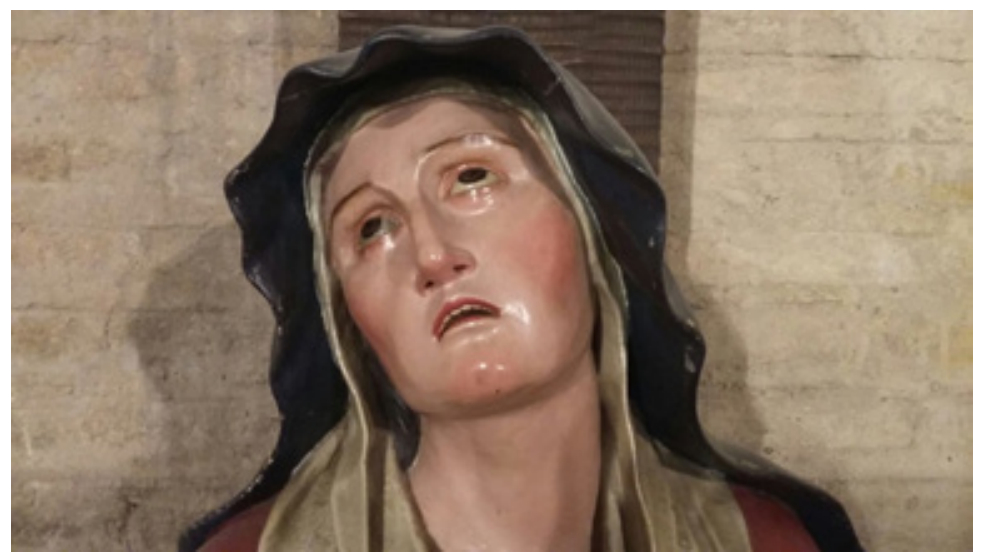

Figura 2. Atribuido a Pedro de Ávila, Busto de Dolorosa (detalle), hacia 1714-1725, parroquia de San Marcos, Sevilla.

Foto: Jesús Romanov López-Alfonso. 


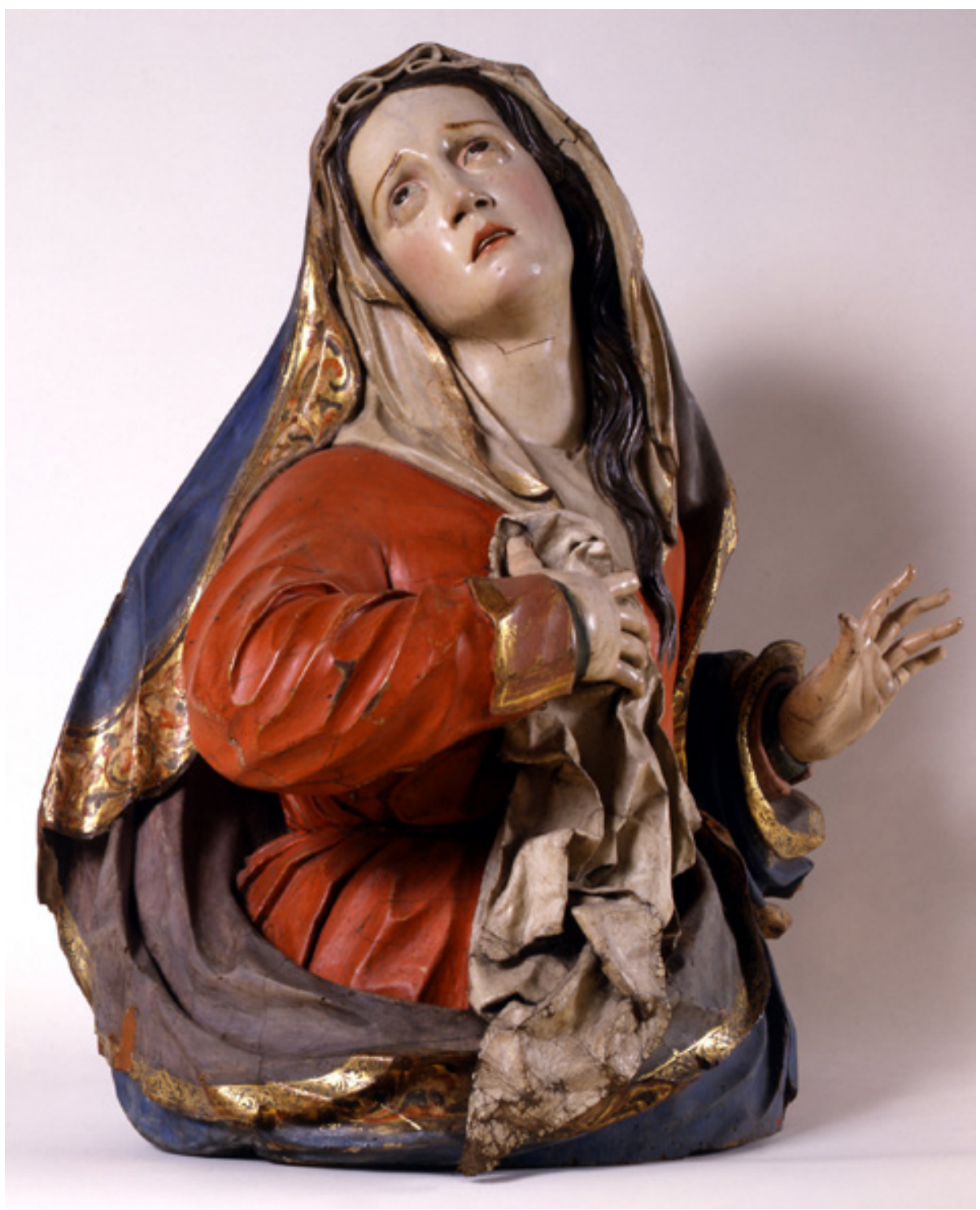

Figura. 3. Atribuido a Pedro de Ávila, Busto de Dolorosa, entre 1714-1739, Museo Nacional de Escultura, Valladolid. Foto: Museo Nacional de Escultura. 


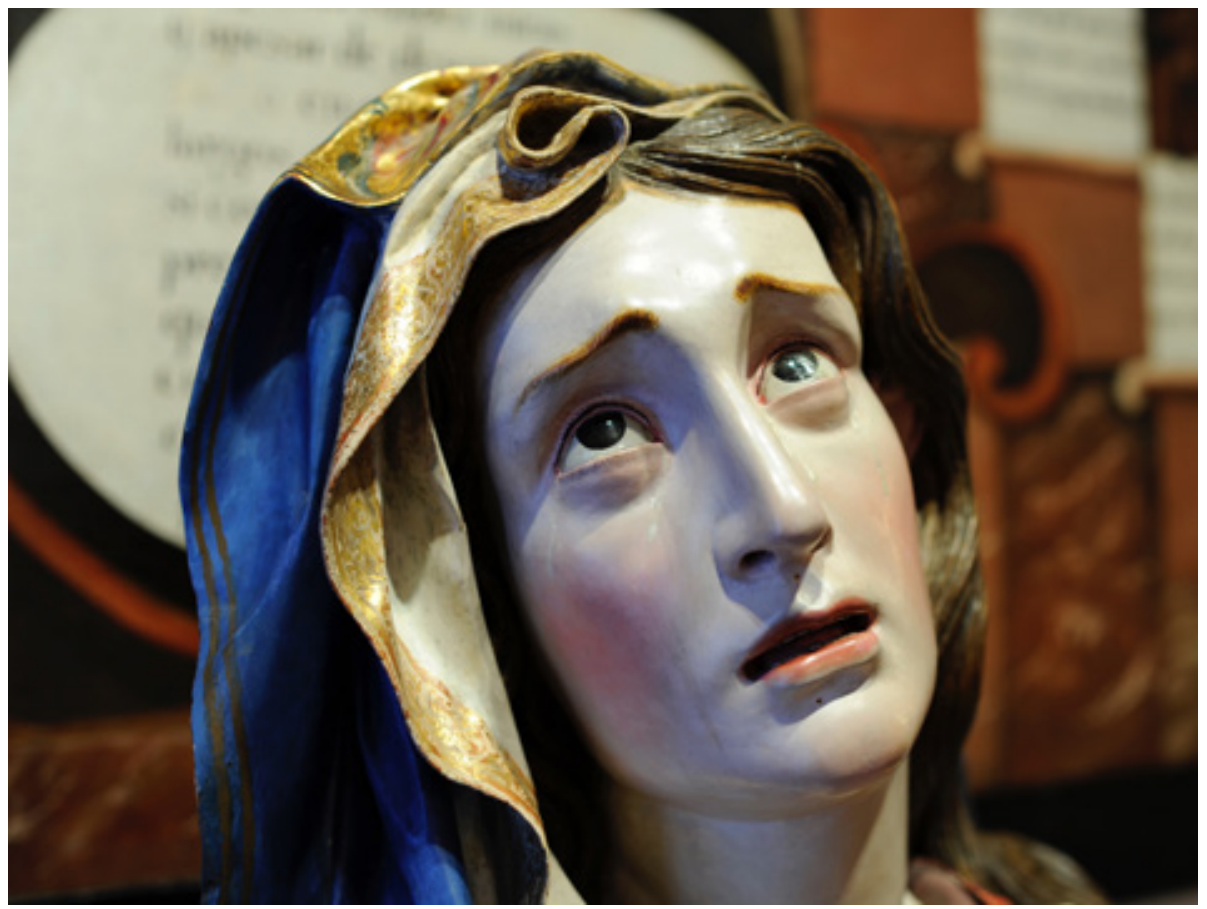

Figura 4. Atribuido a Pedro de Ávila, Busto de Dolorosa (detalle), hacia 1714-1725, Fundación Caja Cantabria, Santillana del Mar (Cantabria). Foto: Fundación Caja Cantabria. 